\title{
The Effect of Smartphone Dependence on Nursing Workplace Spirituality among Hospital Nurses
}

\author{
Hyun-Jin Kim ${ }^{1}$, Mi-Young Chae ${ }^{2}$ \\ ${ }^{1}$ Assistant Professor, Department of Nursing, Suwon Women's University, Korea, \\ hj3428kim@swu.ac.kr \\ 2 Assistant Professor, Department of Nursing, Kwangju Women's University, Korea, \\ mychae@kwu.ac.kr \\ Corresponding author: Mi-Young Chae
}

\begin{abstract}
This study investigates the smartphone dependence of hospital nurses to understand its effect on nursing workplace spirituality. The data were collected on June 11 to July 3, 2021 from 202 nurses who worked at the third general hospital in S City for more than six months and performed direct nursing services. This survey was conducted through a non-face-to-face online survey to prevent corona-related infections. The data were processed using descriptive statistics, t-test, ANOVA, Scheffé, correlation analysis, and multiple regression analysis. As a result of the study, based on the general characteristics, smartphone dependence has negative correlation on marital status, job title, and work experience, and a positive correlation with smartphone usage time per day. Furthermore, nursing workplace spirituality showed a positive correlation with position while the average daily smartphone usage time showed a negative correlation. Smartphone dependence was found to have an effect on the spirituality of hospital nurses in the nursing workplace, and as a result of regression analysis, the explanatory power was $55.0 \%$. Based on these results, it is necessary to develop an intervention program to reduce hospital nurses' dependence on smartphones and to improve nursing workplace spirituality.
\end{abstract}

Keywords: Nurses, Smartphone, Workplace, Spirituality

\section{Introduction}

In a modern society, smartphones go beyond simple phone work, and print and link to groupware by e-mail, Internet search, document storage, application installation, and utilization of application functions, and application creation and other functions can be shared with others[1]. In addition, Korea is an IT powerhouse with a smartphone penetration rate of $95 \%$ that can be said to be the number one in the world[2]. In medical and nursing environments, using smartphones to develop programs to monitor errors related to medication activities[3], develop and apply drug nursing education programs[4], CPR simulation activities, various educational materials for patients among others has been provided[5][6]. As such, various activities and programs based on smartphones are being actively developed and applied to improve hospital work and nurses' work efficiency. However, various physical and mental negative aspects such as smartphone addiction and turtle neck symptoms are revealed due to excessive use of smartphones in various environments[7][8].

Looking at the definition of smartphone dependence, excessive smartphone use increases the salience that the smartphone becomes the most important activity in an individual's life more than any other

Received: September 11, 2021; $1^{\text {st }}$ Review Result: October 25, 2021; $2^{\text {nd }}$ Review Result: December 14, 2021 Accepted: January 29, 2022 
activity, and the control power decreases while using the smartphone, which interferes with daily life[9]. It is said that one in five smartphone users in Korea is at risk of smartphone dependence, and the upward trend is increasing every year[9]. The increase in smartphone use had not only a positive effect on social change to enable global information exchange and communication but also a negative result of dependence on smartphones[9].

The changes in the nursing workplace environment along with the changes in the various medical environments require nurses to adapt to a fast work environment. Workplace spirituality refers to an individual's experience that he or she performs at work, is satisfied with work, and communicates effectively with colleagues[10]. Workplace spirituality is said to directly or indirectly affect organizational performance, efficiency, and the internal values of members[11]. In addition, it is said that there is an improvement effect such as an increase in job satisfaction, work commitment, and organizational commitment for individuals[11]. Nursing workplace spirituality gives meaning to nursing in the workplace environment, the nursing environment, and the nursing field, experiences selfactualization through nursing behavior, feels the perception of values in the organization, and promotes interaction with colleagues. It was said that it can be experience through community consciousness[12]. In previous studies, nursing workplace spirituality has been reported to affect nursing job performance[13] and organizational citizenship behavior[14], so similar results can be expected within organizations.

Even in the nursing workplace, smartphones are used to explain hospitalization to patients, provide information about diseases, and provide various notification services. Also, nurses are increasingly using smartphones rather than discussing problems with colleagues or meeting in person when communicating[15]. This means that the environment in which hospital nurses work interact with the hospital organizational culture and require expertise, skills, teamwork, etc[16]. Decrease of direct communication between colleagues can affect individual values and behaviors within the community or workplace environment[12]. Relationships with colleagues in the workplace, empathy, consideration, and efforts to solve problems are important variables in nursing workplace spirituality[12]. In addition, since a lot of education programs for developing nurses' abilities are provided through smartphones, hospital nurses are also actually using smartphones in a hospital environment a lot. Therefore, even nurses working in hospitals may have physical and mental problems due to smartphone dependence[7].

Physical and mental problems in these hospital environments can affect nurse burnout, stress, and job satisfaction[17], and there is a lack of research on the direct effect of nursing workplace spirituality on job satisfaction[16]. Therefore, it is necessary to study the relevance of nursing workplace spirituality. However, in the current study, most of the researches highlight only the positive aspects of business development and education development related to the nurses and smartphones[3][5][18]. Nursing workplace spirituality is being studied in various ways. Previous studies focused on work performance, organizational behavior change, and turnover intention, and recently, research on the relationship between quality of life and nursing spirituality has been conducted [13][16][19][20]. In their study, it was found that work-personal harmony and relationships with colleagues influence work life. However, this study focused on changes in physical or organizational behaviors such as organizational factors, fatigue, and burnout, or was targeted at nurses returning from cancer after being diagnosed with cancer. Despite the many uses of smartphones by nurses in hospitals, studies on the relationship between smartphones and nursing spirituality are hard to find. Therefore, this study aims to investigate the smartphone dependence of hospital nurses, to understand the influence of these factors on nursing workplace spirituality, and to help improve the positive organizational culture and mental health of nurses working in hospitals. 


\section{Research Method}

\subsection{Study Design \& Purspose}

This study uses a descriptive design to understand hospital nurses' smartphone dependence, confirm the relationship with nursing workplace spirituality, and identify influencing factors..

1. Assess the nurse's smartphone dependence and the level of nursing workplace spirituality..

2. Identify the differences in smartphone dependence and nursing workplace spirituality according to the general characteristics of nurses.

3. Identify the correlation between smartphone dependence and nursing workplace spirituality.

4. To understand the influence of nurses' smartphone dependence on nursing workplace spirituality

\subsection{Research Subjects}

The subjects who agreed to participate in the study after getting their consent were the hospital nurses working at a tertiary general hospital in S city with more than six months of middle school experience and performing direct nursing care. The sample was calculated using the $\mathrm{G}^{*}$ Power 3.1.6 program. For regression analysis, the minimum number of samples was 184 , with a significance level of .05, a power of .95 , and a median effect size of .15. A questionnaire was sent to the subjects, and a total of 202 copies were analyzed except for eight questionnaires in which some data were missing.

\subsection{Data Collection and Ethical Considerations}

For data collection, a non-face-to-face online survey was conducted from June 11 to July 3, 2021, to prevent infections related to COVID-19. The online survey was approved by the IRB, and a recruitment notice was posted on the distribution site. In the announcement, the requirements of the study subjects were specified, and the URL was sent to the subjects who agreed to the questionnaire, and data were collected. The purpose of the study was explained to the selected subjects to which the final participants agreed to for the ethical protection of personal information and rights related to research participation of the subjects. The research was conducted after receiving approval from the $\mathrm{K}$ University Institutional Bioethics Review Committee (1041465-202105-HR-001-15). In the questionnaire, the introduction of the researchers and the purpose of the study were explained, and it was stated that participation in the study can be decided voluntarily. The research results obtained in this study are confidential and not used for purposes other than the research and the intention to discontinue participation can be expressed at any time. The collected data is managed by the researcher, and all research data are subject to Article 19 Paragraph 1 of the Bioethics and Safety Act and Article 15 of the Enforcement Regulations of the Bioethics and Safety Act (records and storage of human subjects research, etc.) It will be safely stored on the researcher's PC with a locking device. It was explained that personal information will be permanently deleted and shredded by Article 16 of the Enforcement Decree of the Personal Information Protection Act. A predetermined coupon was sent to the subjects who completed the questionnaire.

\subsection{Research Tool}

\subsubsection{Smartphone Dependence}

For smartphone dependence, the adult smartphone dependence self-diagnosis scale (S-scale) developed by Kim et al.[21] was used after obtaining the developer's permission. The smartphone dependence scale consists of four sub-factors: 5 items for daily life disorder, 2 items for virtual world orientation, 4 items for withdrawal, and 4 items for tolerance, for a total of 15 items. The scale is on a 
four-point Likert scale ranging from 'not at all ', 'disagree', 'agree', and 'strongly agree'. The total score ranges from 15 to 60, with higher scores indicating higher smartphone dependence. A total score of 39 or less is classified into the general group, 40 to 44 points are classified as a potential risk group, and 45 to 60 points are classified as a high-risk group. The reliability of the tool was Cronbach's $\alpha .94$ in the study of Kim et al.[21]. In this study, Cronbach's $\alpha$ was .87.

\subsubsection{Nursing Workplace Spirituality}

Nursing workplace spirituality was used after obtaining permission from the developer using the nursing workplace spirituality measurement tool developed by Suk[12]. This tool consists of eight items on the meaning of nursing, six items on connection with colleagues, five items on transcendence through nursing work, six items on the inner self, four items on interaction with the work environment, and three items on harmony between organization and individual. It consists of six areas. The scale ranges from one point of 'not at all' to seven points of 'strongly agree' with a total score of 224 points. At the time of development, the overall reliability of the tool was Cronbach's $\alpha$ was .96[12]. In this study, Cronbach's $\alpha$ was .83 .

\subsection{Data Analysis}

For the collected data, frequency analysis and descriptive statistical analysis were performed to identify major variables and general characteristics of subjects using the SPSS/WIN 20.0 (USA) program. Independent sample t-test and ANOVA were performed for differences in major variables according to general characteristics, and Scheffé test was used for post hoc tests. The reliability of the measurement tool was calculated by Cronbach's $\alpha$, and Pearson correlation analysis was performed on the relationship between major research variables. Multiple regression analysis was performed to confirm the effect on nursing workplace spirituality.

\section{Results}

\subsection{General Characteristic of Study Subjects}

The general characteristics of the subjects of this study are shown in [Table 1]. The average age of the study subjects was 32 years old, and the majority were single. As for educational background, $85.6 \%$ (173 people) had a college degree, $30.7 \%$ (42 people) had more than 5 years of study experience and less than 10 years, and $32.2 \%$ (65 people) had 10 years or more. more. By position, general nurses accounted for the most at $81.2 \%$ (164 persons), internal medicine with $43.6 \%$ ( 88 persons), and fixed positions at $49.0 \%$ (99 persons). The average daily smartphone usage time was more than 2 hours and less than 3 hours, with $32.2 \%$ (65 people) taking the most.

[Table 1] General Characteristics of Participants

\begin{tabular}{|l|l|c|c|}
\hline Characteristics & Categories & $\mathrm{n}(\%)$ & Mean \pm SD \\
\hline \multirow{4}{*}{ Age (yr) } & $<30$ & $56(27.7)$ & $32.86 \pm 4.89$ \\
\cline { 2 - 4 } & $30 \sim 39$ & $121(59.9)$ & \\
\cline { 2 - 4 } & $\geq 40$ & $25(12.4)$ & \\
\hline \multirow{2}{*}{ Marital status } & Not married & $124(61.4)$ & \\
\cline { 2 - 4 } & Married & $78(38.6)$ & \\
\hline \multirow{2}{*}{ Religion } & Yes & $72(35.60$ & \\
\cline { 2 - 4 } & No & $130(64.4)$ & \\
\hline Education level & University & $173(85.6)$ & \\
\hline
\end{tabular}




\begin{tabular}{|c|c|c|c|}
\hline & Graduate school & $29(14.4)$ & \\
\hline \multirow{4}{*}{ Work period(yr) } & $<3$ & $33(16.3)$ & $2.79 \pm 1.06$ \\
\hline & $\geq 3 \sim<5$ & $42(20.8)$ & \\
\hline & $\geq 5 \sim<10$ & $62(30.7)$ & \\
\hline & $\geq 10$ & $65(32.2)$ & \\
\hline \multirow{2}{*}{ Working position } & Staff nurse & $164(81.2)$ & \\
\hline & $\geq$ Charge nurse & $38(18.8)$ & \\
\hline \multirow{4}{*}{ Working unit } & Internal & $88(43.6)$ & \\
\hline & Surgical & $31(15.3)$ & \\
\hline & OPD & $26(12.9)$ & \\
\hline & Special department & $57(28.2)$ & \\
\hline \multirow{2}{*}{ Working type } & Fixed & $99(49.0)$ & \\
\hline & Shift & $103(51.0)$ & \\
\hline \multirow{4}{*}{$\begin{array}{l}\text { Average } \\
\text { smartphone } \\
\text { usage time } \\
\text { (hr/day) }\end{array}$} & $<2$ & $33(16.3)$ & $2.59 \pm 1.02$ \\
\hline & $\geq 2 \sim<3$ & $65(32.2)$ & \\
\hline & $\geq 3 \sim<4$ & $56(27.7)$ & \\
\hline & $\geq 4$ & $48(23.8)$ & \\
\hline \multirow{5}{*}{$\begin{array}{l}\text { The most used } \\
\text { functions on } \\
\text { a smartphone }\end{array}$} & Voice call & $21(10.4)$ & \\
\hline & Text, chatting(Kakaotalk, Line, etc.) & $47(23.3)$ & \\
\hline & $\begin{array}{l}\text { Internet shopping, web surfing, watching music \& } \\
\text { movies, game }\end{array}$ & $34(16.8)$ & \\
\hline & SNS (facebook, instagram, cafe, blog activity etc.) & $88(43.6)$ & \\
\hline & For business & $12(5.9)$ & \\
\hline
\end{tabular}

$\mathrm{OPD}=$ Outpatient department.

\subsection{Smartphone Dependence and Nursing Workplace Spirituality of Study Subjects}

[Table 2] shows the subjects' smartphone dependence and nursing workplace spirituality. Smartphone dependence was $2.52 \pm .50$ out of 4 points, and nursing workplace spirituality was $4.52 \pm 1.02$ out of 7 points.

[Table 2] Smartphone Dependence, Nursing Workplace Spirituality

\begin{tabular}{|l|c|c|c|c|c|}
\hline Variables & Items & Mean & SD & Total Mean \pm SD & Range \\
\hline Smartphone dependence & 15 & 2.52 & 0.50 & $35.48 \pm 6.87$ & $1-4$ \\
\hline Nursing workplace spirituality & 32 & 4.52 & 1.02 & $160.87 \pm 21.9$ & $1-7$ \\
\hline
\end{tabular}

\subsection{Differences between Smartphone Dependence and Nursing Workplace Spirituality according to the General Characteristics of Study Subjects}

[Table 3] shows the differences between smartphone dependence and nursing workplace spirituality according to the general characteristics of the study subjects. The subjects' general characteristics that showed a significant difference with smartphone dependence weew unmarried $(t=2.57, p=.011)$, work experience $(\mathrm{F}=2.82, \mathrm{p}=.040)$, position $(\mathrm{t}=3.36, \mathrm{p}=.001)$, and average smartphone usage time per day $(\mathrm{F}=5.273, \mathrm{p}=.002)$. In the case of unmarried people, the dependence on smartphones was higher than that of married people, and there was a difference in scores increasing in the order of 3 to 5 years, 5 to 10 years, and 10 years or more, compared to those with less than 3 years of work experience. The position of the general nurse was higher than that of the head nurse. The average daily smartphone usage time was higher when 4 hours or more were used, and as a result of post-mortem analysis, smartphone usage for three to four hours and smartphone usage for four hours or more were higher than those for 
smartphone use less than two hours. Nursing workplace spirituality according to the general characteristics of the study subjects was higher than that of general nurses according to the position $(\mathrm{t}=-$ $2.647, \mathrm{p}=.009)$.

[Table 3] Smartphone Dependence, Nursing Workplace Spirituality according to General Characteristics

\begin{tabular}{|c|c|c|c|c|c|c|}
\hline \multirow{2}{*}{ Characteristics } & \multirow{2}{*}{ Categories } & \multirow{2}{*}{$\mathrm{n}(\%)$} & \multicolumn{2}{|c|}{ Smartphone dependence } & \multicolumn{2}{|c|}{ Nursing workplace spirituality } \\
\hline & & & Mean \pm SD & $\mathrm{t}$ or $\mathrm{F}(p)$ & Mean \pm SD & $\mathrm{t}$ or $\mathrm{F}(p)$ \\
\hline \multirow{3}{*}{ Age(yr) } & $<30$ & $56(27.7)$ & $36.39 \pm 5.86$ & $2.389(.094)$ & $140.08 \pm 28.69$ & $2.063(.130)$ \\
\hline & $30 \sim 39$ & $121(59.9)$ & $35.61 \pm 6.98$ & & $144.86 \pm 33.99$ & \\
\hline & $\geq 40$ & $25(12.4)$ & $32.84 \pm 8.16$ & & $155.96 \pm 32.93$ & \\
\hline \multirow{2}{*}{ Marital status } & Not married & $124(61.4)$ & $36.4 \pm 6.60$ & $2.57(.011)$ & $141.81 \pm 32.34$ & $-1.710(.089)$ \\
\hline & Married & $78(38.6)$ & $33.9 \pm 7.05$ & & $149.84 \pm 32.75$ & \\
\hline \multirow{2}{*}{ Religion } & Yes & $72(35.60$ & $34.9 \pm 7.48$ & $-.895(.372)$ & $149.40 \pm 32.85$ & $1.457(.147)$ \\
\hline & No & $130(64.4)$ & $35.80 \pm 6.52$ & & $142.43 \pm 32.40$ & \\
\hline \multirow{2}{*}{$\begin{array}{l}\text { Education } \\
\text { level }\end{array}$} & University & $173(85.6)$ & $35.80 \pm 6.53$ & $1.642(.102)$ & $143.18 \pm 32.15$ & $-1.851(.066)$ \\
\hline & Graduate school & $29(14.4)$ & $33.55 \pm 8.52$ & & $155.24 \pm 34.31$ & \\
\hline \multirow{4}{*}{$\begin{array}{l}\text { Work } \\
\text { period(yr) }\end{array}$} & $<3$ & $33(16.3)$ & $36.63 \pm 5.67$ & $2.820(.040)$ & $139.54 \pm 37.59$ & $1.060(.367)$ \\
\hline & $\geq 3 \sim<5$ & $42(20.8)$ & $36.78 \pm 6.08$ & & $141.33 \pm 23.72$ & \\
\hline & $\geq 5 \sim<10$ & $62(30.7)$ & $36.06 \pm 6.00$ & & $144.54 \pm 26.96$ & \\
\hline & $\geq 10$ & $65(32.2)$ & $33.50 \pm 8.26$ & & $150.30 \pm 39.12$ & \\
\hline \multirow{2}{*}{$\begin{array}{l}\text { Working } \\
\text { position }\end{array}$} & Staff nurse & $164(81.2)$ & $36.25 \pm 6.83$ & $3.36(.001)$ & $142.03 \pm 32.26$ & $-2.647(.009)$ \\
\hline & $\geq$ Charge nurse & $38(18.8)$ & $32.18 \pm 6.11$ & & $157.36 \pm 31.80$ & \\
\hline \multirow{4}{*}{ Working unit } & Internal & $88(43.6)$ & $35.86 \pm 6.57$ & $.286(.835)$ & $143.88 \pm 30.78$ & $.276(.843)$ \\
\hline & Surgical & $31(15.3)$ & $34.74 \pm 7.82$ & & $141.70 \pm 36.84$ & \\
\hline & OPD & $26(12.9)$ & $34.84 \pm 5.47$ & & $146.11 \pm 33.19$ & \\
\hline & Special department & $57(28.2)$ & $35.59 \pm 7.46$ & & $147.70 \pm 33.47$ & \\
\hline \multirow{2}{*}{ Working type } & Fixed & $99(49.0)$ & $35.85 \pm 5.85$ & $.760(.448)$ & $142.41 \pm 33.12$ & $-1.068(.287)$ \\
\hline & Shift & $103(51.0)$ & $35.12 \pm 7.75$ & & $147.32 \pm 32.17$ & \\
\hline \multirow{4}{*}{$\begin{array}{l}\text { Average } \\
\text { smartphone } \\
\text { usage time } \\
\text { (hr/day) }\end{array}$} & $<2$ & $33(16.3)$ & $31.75 \pm 7.05^{\mathrm{a}}$ & $\begin{array}{c}5.273(.002) \\
\mathrm{a}<\mathrm{c}, \mathrm{d}\end{array}$ & $154.30 \pm 31.23$ & $2.463(.064)$ \\
\hline & $\geq 2 \sim<3$ & $65(32.2)$ & $35.13 \pm 6.87^{\mathrm{b}}$ & & $147.32 \pm 29.53$ & \\
\hline & $\geq 3 \sim<4$ & $56(27.7)$ & $36.35 \pm 5.64^{\mathrm{c}}$ & & $144.82 \pm 35.10$ & \\
\hline & $\geq 4$ & $48(23.8)$ & $37.50 \pm 7.20^{\mathrm{d}}$ & & $135.31 \pm 33.20$ & \\
\hline \multirow{5}{*}{$\begin{array}{l}\text { The most used } \\
\text { functions on } \\
\text { smartphones }\end{array}$} & Voice call & $21(10.4)$ & $32.57 \pm 8.13$ & $1.165(.327)$ & $153.57 \pm 25.60$ & $.414(.799)$ \\
\hline & $\begin{array}{l}\text { Text, chating } \\
\text { (kakaotalk, line, etc) }\end{array}$ & $47(23.3)$ & $35.70 \pm 5.81$ & & $144.36 \pm 27.99$ & \\
\hline & $\begin{array}{l}\text { Internet shopping, } \\
\text { web surfing,watching } \\
\text { music/movies, game }\end{array}$ & $34(16.8)$ & $36.50 \pm 5.21$ & & $143.14 \pm 30.46$ & \\
\hline & $\begin{array}{l}\text { SNS(facebook, } \\
\text { instagram, cafe, } \\
\text { blog activity etc) }\end{array}$ & $88(43.6)$ & $35.60 \pm 7.81$ & & $143.95 \pm 36.70$ & \\
\hline & For business & $12(5.9)$ & $36.00 \pm 4.19$ & & $144.00 \pm 37.57$ & \\
\hline
\end{tabular}

a,b,c,d=Scheffé test; $\mathrm{OPD}=$ Outpatient department.

\subsection{The Relationship between the Subject's Smartphone Dependence and Nursing Workplace Spirituality}

[Table 4] shows the correlation between the subjects' smartphone dependence and nursing workplace spirituality. The subjects' smartphone dependence and nursing workplace spirituality $(r=-.74 \mathrm{p}<.001)$ showed a very strong negative correlation. It was found that the higher the subjects' smartphone dependence, the lower the nursing workplace spirituality. In general characteristics, smartphone 
dependence and marital status $(\mathrm{r}=-.18, \mathrm{p}<.005)$, job title $(\mathrm{r}=.-.23, \mathrm{p}<.001)$, and work experience $(\mathrm{r}=-.17$ $\mathrm{p}<.005)$ showed a negative correlation while the average daily smartphone usage time $(\mathrm{r}=.25, \mathrm{p}<.001)$ showed a positon correlation. In the general characteristics of nursing workplace spirituality, there was a positive correlation with the position $(\mathrm{r}=.618, \mathrm{p}<.005)$ and a negative correlation with the average daily smartphone use time $(\mathrm{r}=-.18, \mathrm{p}<.001)$.

[Table 4] Correlation between Smartphone Dependence and Nursing Workplace Spirituality

\begin{tabular}{|c|c|c|c|c|c|c|}
\hline Variables & $\begin{array}{c}\text { Smartphone } \\
\text { dependence } \\
\text { r(p) }\end{array}$ & $\begin{array}{c}\text { Nursing } \\
\text { Workplace } \\
\text { Spirituality } \\
\text { r(p) }\end{array}$ & $\begin{array}{c}\text { Married } \\
\mathrm{r}(\mathrm{p})\end{array}$ & $\begin{array}{c}\text { Working } \\
\text { position } \\
\mathrm{r}(\mathrm{p})\end{array}$ & $\begin{array}{l}\text { Work period } \\
\quad \mathrm{r}(\mathrm{p})\end{array}$ & $\begin{array}{c}\text { Average } \\
\text { smartphone } \\
\text { usage time } \\
\text { (per day) } \\
\text { r(p) }\end{array}$ \\
\hline Smartphone dependence & 1 & & & & & \\
\hline $\begin{array}{l}\text { Nursing Workplace } \\
\text { spirituality }\end{array}$ & $\begin{array}{c}-.74 \\
(<.001)\end{array}$ & 1 & & & & \\
\hline Married & $\begin{array}{c}-.18 \\
(<.005) \\
\end{array}$ & $\begin{array}{c}.12 \\
(.089) \\
\end{array}$ & 1 & & & \\
\hline Working position & $\begin{array}{c}-.23 \\
(<.001) \\
\end{array}$ & $\begin{array}{c}.18 \\
(<.001)\end{array}$ & & 1 & & \\
\hline Work period & $\begin{array}{c}-.17 \\
(<.005) \\
\end{array}$ & $\begin{array}{c}.12 \\
(.084) \\
\end{array}$ & & & 1 & \\
\hline $\begin{array}{l}\text { Average, smartphone } \\
\text { usage time (per day) }\end{array}$ & $\begin{array}{c}.25 \\
(<.001)\end{array}$ & $\begin{array}{c}-.18 \\
(<.001)\end{array}$ & & & & 1 \\
\hline
\end{tabular}

\subsection{Effect of Subjects' Smartphone Dependence on Nursing Workplace Spirituality}

To identify the factors affecting nursing workplace spirituality, multiple regression analysis was conducted using the subject's nursing workplace spirituality as a dependent variable and the position and average daily smartphone use time as independent variables, which are general variables that showed differences in nursing workplace spirituality. Position, which is a general characteristic variable, was implemented by dummyizing this variable as a nominal scale. As a result of the regression analysis, the VIF (variation inflation factor) value was 1.136, which was less than 10, so there was no problem of multicollinearity. Also, the tolerance limit was found to be .862 . As a result of multiple regression analysis, the explanatory power was $55.0 \%$, and the factor influencing the nursing workplace spirituality was smartphone dependence $(\beta=-3.56, p<.001)$. In the residual analysis results, the linearity, normality, and equal variance of the model were all satisfied. Therefore, it was confirmed that all assumptions of the regression equation were satisfied. As a result of the validation of the nursing workplace spirituality model, the regression model was significant $(\mathrm{F}=50.04, \mathrm{p}<.001)$ [Table 5].

[Table 5] Factors Influencing Nursing Workplace Spirituality

\begin{tabular}{|c|c|c|c|c|c|}
\hline Variables & B & S.E. & B & $\mathrm{t}$ & $\mathrm{p}$ \\
\hline (constant) & 270.899 & 11.369 & & 23.828 & $<.001$ \\
\hline Smartphone dependence & -3.567 & 0.242 & -0.751 & -14.737 & $<.001$ \\
\hline \multicolumn{7}{|l|}{} \\
\hline
\end{tabular}

\section{Discussion}

The purpose of this study was to provide basic data for developing an intervention program to improve nursing workplace spirituality. In this discussion, we will focus on smartphone dependence, which is a 
factor influencing nursing workplace spirituality. Nursing workplace spirituality in this study was 4.52 out of 7, which was above average. This was similar to the score of 4.54 in the study of Lim and Kim[22] and 4.49 in the study of Kown and $\mathrm{Oh}[23]$. It is thought that the study subjects were nurses working in general hospitals as in this study, and similar to the previous study[22][23] targeting nurses with more than 1 year of experience. However, in a study by Roh and Suh[24], which measured workplace spirituality of office workers in a company, the result was lower than 4.87 points. This is because the medical organization of the hospital is constantly changing the medical environment due to the constant development of new medicines, medical devices, and new drugs, and the clinical nurses in the hospital are learning it and continuously self-develop[25]. Therefore, it is considered that the burden of work in the organization of hospital nurses is lower than that of general office workers. In addition, shift work nurses, who accounted for $51 \%$ of this study, suffer from chronic physical fatigue, and stress in the organization due to lack of nursing personnel leads to negative results such as turnover or resignation[16]. This is thought to be a result of reflecting the unique characteristics of the nursing profession, and it is necessary to prepare a plan for nurses to immerse themselves in the organization and improve the workplace spirituality by reflecting the complex situation of hospital nursing organization along with repeated studies.

In this study, nursing workplace spirituality according to general characteristics was higher than that of general nurses according to the position $(\mathrm{t}=-2.647, \mathrm{p}=.009)$. This is similar to the results of this study as the higher the clinical experience, the higher the position, compared with the results of Jin et al.[16]'s study of 11 years or more of clinical experience showing significantly higher nursing workplace spirituality. This is thought to be due to the higher the position, the higher the understanding and loyalty to the organization.

The factor that has the greatest influence on the spirituality of nursing workplaces is the dependence on smartphones, with a score of 35.48 out of 60 . The higher the smartphone dependence score, the higher the smartphone dependence tendency and 39 or less is the general group[14]. Thus, the subjects of this study, on the average, belong to the general group. Since there is no previous study on smartphone dependence of hospital nurses, there is no comparable group, so it is suggested that further study be conducted by expanding the number of subjects.

The research result that the risk of smartphone addiction increases as the time spent using smartphones increases[26] is a problem caused by the increase in information retrieval ability, diversity, and simplicity with the development of smartphones[27]. The increase can have a variety of effects. Nurses with a high level of spirituality in the nursing workplace have a high level of interaction with their colleagues and find pleasure in the workplace[28]. However, nurses who are highly dependent on smartphones have less interaction with co-workers, which will affect not only enjoyment at work but also spirituality in the nursing workplace. In addition, the pleasure of nurses at work affects the goals and values of the organization and motivates them to work passionately[28]. Therefore, it is considered that each hospital organization needs to investigate the degree of dependence of nurses on smartphones, reduce their dependence on smartphones, and make efforts to increase nursing workplace spirituality.

The improvement of smartphone technology can improve the performance of nurses and the quality of care provided to patients[29]. In addition, it is possible to increase the efficiency of fast communication with multidisciplinary medical personnel in the medical field[30]. Nursing use of smartphones at work plays a large role as a support tool, but if used for personal purposes (internet surfing, social networks, e-mail) rather than medical purposes, it negatively affects interdisciplinary communication and nurses' work performance lowers[31]. In this study, the use of smartphones was found to be the most with social media activity rather than work. Of course, this study did not ask questions about functions used when working in hospitals but surveyed both daily life and work life, so it cannot be asserted that it is consistent with the results of previous studies. However, considering the increase in smartphone use in the medical field, it can be inferred that it can negatively affect nurses' 
work performance and communication. Therefore, excessive use of smartphones interferes with communication and concentration in the organization and is one of the matters that need to be managed within the medical organization[31]. Therefore, in future studies, it is suggested to conduct a study on the current status of smartphone use and organizational performance of nurses during their work.

Combining this study, it can be seen that active measures are required, including the preparation of organizational communication activation measures to reduce dependence on smartphones so that hospital nurses can form a positive nursing workplace spirituality. In addition, hospital nurses need to recover from physical and mental problems caused by smartphone dependence, so an intervention program to solve this should be considered. Reducing dependence on smartphones is an important task in nurturing healthy emotional organization members by improving nursing workplace spirituality, and since this is not a primary problem in hospital organizations, but a general problem in society, a countermeasure at the social level is necessary.

\section{Conclusions and Suggestions}

This study investigated the smartphone dependence of hospital nurses and identified the effects of these factors on nursing workplace spirituality. In this way, it was attempted to help nurses' mental health and to contribute to a positive organizational culture by identifying the problems caused by the dependence of hospital nurses on smartphones. As a result, smartphone dependence was identified as a factor influencing hospital nurses' spirituality in the nursing workplace. As smartphone dependence is an important factor in nursing workplace spirituality, it was found that preparing a plan to reduce smartphone dependence to improve nursing workplace spirituality, which is an indicator of positive organizational culture, is essential for a healthy organizational culture. Therefore, it is considered that positive changes in the organization are more urgently needed to prepare a way to activate communication opportunities in the organization to reduce the dependence on smartphones of nurses working in hospitals. As a limitation of this study, it is not possible to assert the results of this study by investigating not only the use of smartphones when working in hospitals but also in daily life activities. Therefore, in future research, it is suggested that the use of smartphones should be investigated by separating the work environment and daily life. In addition, it is suggested to analyze the factors affecting nursing workplace spirituality of nurses working in other industries or communities as well as hospital nurses focusing on smartphone dependence. As there is no related prior research, there is a need to expand the research subject and conduct further research. Finally, the development and application of interventional research is proposed to improve the nursing workplace spirituality of hospital nurses.

\section{References}

[1] https://en.wikipedia.org/wiki/Smartphone/, July 4 (2021)

[2] https://biz.chosun.com/site/data/html_dir/2019/02/06/2019020600746.html, Feb 9 (2021)

[3] M. S. Kim, Development and effectiveness of smartphone application for the medication confirmation of high-alert medications, Korean Journal of Adult Nursing, (2014), Vol.26, No.3, pp.253-265, DOI: 10.7475/kjan.2014.26.3.253

[4] S. I. Choi, B. R. Jeon, H. B. Shin, Y. K. Lee, Y. W. Lee, Smartphone-based mobile web to provide laboratory test reference information, The Journal of Laboratory Medicine and Quality Assurance, (2014), Vol.36, No.4, pp.205-209, DOI: $10.15263 / \mathrm{jlmqa}$.2014.36.4.205 
[5] M. Y. Pyo, J. Y. Kim, J. O. Sohn, E. S. Lee, H. S. Kim, K. O. Kim, H. J. Park, M. J. Kim, G. H. An, J. R. Yang, J. H. Yu, Y. A. Kim, H. J. Kim, M. N. Choi, The effects of an advanced cardiac life support training via smartphone's simulation application on nurses' knowledge and learning satisfaction, Journal of Korean Clinical Nursing Research, (2012), Vol.18, No.2, pp.228-238, DOI: 10.22650/JKCNR.2012.18.2.228

[6] Y. H. Lee, J. H. Kim, J. K. Kim, K. P. Min, E. Y. Jung, D. K. Park, Smart phone based personalized menu management system for diabetes patient, The Journal of the Korea Contents Association, (2010), Vol.10, No.12, pp.1-9, DOI: 10.5392/JKCA.2010.10.12.001

[7] Y. G. Choi, Accompanying+being together: health checklist- you're a cell phone addict who gets anxious without a cell phone!, Health News, (2010), Vol.34, No.8, pp.34-35.

[8] The survey on smartphone overdependence, Ministry of Science and ICT \& National Information Society Agency, pp.1$331,(2019)$

[9] S. Lee, An analysis on the mental health of adolescent addicted to smartphone, Journal of Youth Welfare, (2018), Vol.20, No.3, pp.47-67, DOI: 10.19034/KAYW.2018.20.3.03

[10] D. P. Ashmos, D. Duchon, Spirituality at work: a conceptualization and measure, Journal of Management Inquiry, (2000), Vol.9, No.2, pp.134-45, DOI: 10.1177/105649260092008

[11] J. Milliman, A. J Czaplewski, J. Ferguson, Workplace spirituality and employee work attitudes: an exploratory empirical assessment, Journal of Organizational Change Management, (2003), Vol.16, No.4, pp.426-447, DOI: $10.1108 / 09534810310484172$

[12] J. W. Suk, Development of measuring instrument for nursing workplace spirituality, Sahmyook University, Ph.D dissertation, pp.1-95, (2015)

[13] G. M. Noh, M. S. Yoo, Effects of workplace spirituality and organizational citizenship behavior on nursing performance, Journal of Korean Academy of Nursing Administration, (2016), Vol.22, No.3, pp.251-259, DOI: 10.11111/jkana.2016.22.3.251

[14] F. Kazemipour, S. M. Amin, The impact of workplace spirituality dimensions on organisational citizenship behaviour among nurses with the mediating effect of affective organisational commitment, Journal of Nursing Management, (2012), Vol.20, No.8, pp.1039- 1048, DOI: 10.1111/jonm.12025

[15] J. Korkeila, Internetriippuvuus - milloin haitalliseen käyttöön pitää puuttua? [Internet addiction - when should one intervene in harmful usage?], Duodecim, (2012), Vol.128, No.7, pp.741-748.

[16] J. H. Jin, H. O. Ju, K. S. Kim, Y. M. Park, Effects of nursing workplace spirituality on job satisfaction, burnout and turnover intention among general hospital nurses, Journal of Korean Clinical Nursing Research, (2017), Vol.23, No.2, pp.142-150, DOI: 10.22650/JKCNR.2017.23.2.142

[17] H. S. Park, K. N. Kim, Factors affecting burnout in ICU nurses, Journal of Korean Academy of Fundamentals of Nursing, (2010), Vol.17, No.3, pp.409-418, UCI: G704-001689.2010.17.3.011

[18] M. S. Kim, S. Kim, H. K. Jung, M. H. Kim, Factors influencing intention to use smart-based continuing nurse education, Journal of Korean Academy of Fundamentals of Nursing, (2016), Vol.23, No.1, pp.51-60, DOI: 10.7739/jkafn.2016.23.1.51

[19] F Kazemipour, S Mohamad Amin, B Pourseidi, Relationship between workplace spirituality and organizational citizenship behavior among nurses through mediation of affective organizational commitment, Journal of Nursing Scholarship, (2012), Vol.44, No.3, pp.302-310, DOI: 10.1111/j.1547-5069.2012.01456.x

[20] J. H. Jin, E. J. Lee, Effect of workplace spirituality on quality of work life of nurse cancer survivors in South Korea, Asia-Pacific Journal of Oncology Nursing, (2020), Vol.7, No.4, pp.346-354, DOI: 10.4103/apjon.apjon_36_20

[21] D. I. Kim, Y. J. Jung, Y. H. Lee, B. K. Kim, H. J. Jeonk, Develpment and validation of youth smartphone addiction self-report scale, Korean Journal of Counseling, (2016), Vol.17, No.3, pp.319-335, DOI: $10.15703 / \mathrm{kjc} .17 .3 .201606 .319$

[22] J. M. Lim, J. K. Kim, The Influence of nursing workplace spirituality and resilience of hospital nurses on professional quality of life, The Journal of the Korea Contents Association, (2020), Vol.20, No.2, pp.487-498, DOI: 
10.5392/JKCA.2020.20.02.487

[23] K. Y. Kown, P. J. Oh, Effects of nursing workplace spirituality and self-efficacy on the patient safety management activities of nurses, Journal of Korean Academy of Nursing Administration, (2019), Vol.25, No.2, pp.106-114, DOI: 10.11111/jkana.2019.25.2.106

[24] S. C. Rho, Y. W. Suh, The five-factor model of workplace spirituality: A conceptualization and scale development, Korean Journal of Industrial and Organizational Psychology, (2014), Vol.27, No.2, pp.419-447, DOI: 10.24230/ksiop.27.2.201405.419

[25] J. W. Suk, M. S. Koh, Development of nursing workplace spirituality instrument: confirmatory factor analysis, Journal of Korean Academy of Nursing Administration, (2016), Vol.22, No.1, pp.99-108, DOI: 10.11111/jkana.2016.22.1.99

[26] E. J. Song, The Relationship between the usingMobile Phone and Mental HealthState of High School Students, Journal of Korean Academy of Psychiatric and Mental Health Nursing, (2006), Vol.15, No.3, pp.325-333, UCI: G704001695.2006.15.3.004

[27] K. H. Hwang, Y. S. Yoo, O. H. Cho, Smartphone overuse and upper extremity pain, anxiety, depression, and interpersonal relationships among college students, The Journal of the Korea Contents Association, (2012), Vol.12, No.10, pp.365-375, DOI: 10.5392/JKCA.2012.12.10.365

[28] R. Norouzi, S. Dargahi, N. Aeyadi, M. Sarhaddi, The association between workplace spirituality and job stress with occupational ethics through mediating role of job enthusiasm among nurses in Zahedan city, 2017, Journal of Occupational Health and Epidemiology, (2018), Vol.7, No.1, pp.3-10, DOI: 10.29252/johe.7.1.3

[29] M. Fiorinelli, S. D. Mario, A. Surace, M. Mattei, C. Russo, G. Villa, S. Dionisi, E. D. Simone, N. Giannetta, M. D. Muzio, Smartphone distraction during nursing care: systematic literature review, Applied Nursing Research, (2021), Vol.58, p.151405, DOI: 10.1016/j.apnr.2021.151405

[30] B. Patel, M. Johnston, N. Cookson, D. King, S. Arora, A. Darzi, Interprofessional communication of clinicians using a mobile phone app: a randomized crossover trial using simulated patients, Journal of Medical Internet Research, (2016), Vol.18, No.4, pp.1-13, DOI: 10.2196/jmir.4854

[31] Y. Fujino, R. Kawamoto, Effect of information and communication technology on nursing performance, Computers, Informatics, Nursing, (2013), Vol.31, No.5, pp.244-250, DOI: 10.1097/NXN.0b013e3182842103 